\title{
Fibrinogen Degradation Product Fragment D Induces Endothelial Cell Detachment by Activation of Cell-mediated Fibrinolysis
}

\author{
Ming Ge, * Gexin Tang, * Thomas J. Ryan, ${ }^{*}$ and Asrar B. Malik * \\ *Department of Physiology and Cell Biology, The Albany Medical College of Union University, Albany, New York 12208; and \\ ${ }^{\ddagger}$ Wadsworth Center, New York State Department of Health, Empire State Plaza, Albany, New York 12201-0509
}

\begin{abstract}
We studied the effects of fibrinogen degradation product (FDP) fragment D on endothelial monolayer integrity and the mechanisms of fragment D-induced endothelial cell detachment from the substratum. Incubation of bovine pulmonary artery endothelial cells (BPAEC) with fragment D caused concentration- and time-dependent cell detachment from the substratum. The optimal response occurred at fragment $D$ concentrations of $2 \mu \mathrm{M}$ and required an incubation time of $24 \mathrm{~h}$. BPAEC challenged with fragment $D$ increased the concentration and activity of urokinase-type plasminogen activator (uPA) in the conditioned medium within 2 to $4 \mathrm{~h}$ of incubation. Fragment $D$ also induced the release of tissue-type plasminogen activator, but to a lesser extent than uPA. Fragment D concurrently increased plasminogen activator (PA) activity in a concentration-dependent manner. Increased PA activity was followed by augmentation of cell-associated plasmin activity and subsequent increase in the degradation of ${ }^{125} \mathrm{I}$-fibrinogen and ${ }^{125}$ I-vitronectin precoated in the subendothelial matrix. Pretreatment of BPAEC with anti-uPA antibody, and inhibitors of uPA (dansyl-GGACK) and plasmin (aprotinin) prevented $\sim 60 \%$ of the fragment $D$-induced endothelial cell detachment. We conclude that FDP fragment $D$ increases secretion of endothelial PAs and enhances the generation of plasmin, thereby contributing to proteolysis of extracellular matrix and endothelial cell detachment. Fragment $D$ may be a critical mediator linking activation of fibrinolysis to vascular endothelial injury in inflammatory disorders. (J. Clin. Invest. 1992. 90:2508-2516.) Key words: endothelium • fibrinogen degradation products $\bullet$ fragment $D \cdot$ fibrinolysis • plasminogen activators $\bullet$ cell detachment $\bullet$ plasmin $\bullet$ proteolysis
\end{abstract}

\section{Introduction}

Fibrin( ogen ) degradation products (FDPs) ${ }^{1}$ generated during fibrinolysis have been implicated in tissue inflammation asso-

Address correspondence to A. B. Malik, The Albany Medical College, 47 New Scotland Ave., Albany, NY 12208.

Received for publication 26 February 1992 and in revised form 23 July 1992.

1. Abbreviations used in this paper: $\mathrm{Ab}$, antibody; ARDS, adult respiratory distress syndrome; BPAEC, bovine pulmonary artery endothelial cells; dansyl GGACK, dansyl Glu-Gly-Arg chloromethyl ketone; DMEM, Dulbecco's modified essential medium; FDP, fibrinogen degradation product; PA, plasminogen activator; PAI, plasminogen activator inhibitor; EPA, tissue-type plasminogen activator; uPA, urokinase-type plasminogen activator.

J. Clin. Invest.

(c) The American Society for Clinical Investigation, Inc. 0021-9738/92/12/2508/09 \$2.00

Volume 90, December 1992,.2508-2516 ciated with the adult respiratory distress syndrome (ARDS), disseminated intravascular coagulation, and septic shock (14). Studies indicate that plasma concentrations of FDP fragment $\mathrm{D}$ are markedly elevated in these disorders $(1,4)$. Saldeen (5) and Malik (3) have suggested that activation of fibrinolysis, and resulting generation of FDPs including fragment $\mathrm{D}$, contributes to lung vascular injury. Infusion of fragment $\mathrm{D}$ into rabbits induced progressive thrombocytopenia, pulmonary dysfunction, and increased pulmonary vascular permeability, changes that were characteristic of $\operatorname{ARDS}(5,6)$.

Studies also indicate that fragment $D$ has important effects on the endothelial cell barrier. Dang et al. (8) reported that fragment $\mathrm{D}$ detached bovine aorta endothelial monolayers from the substratum. Our previous studies indicated that fragment D increased bovine pulmonary artery endothelial monolayer permeability to ${ }^{125} \mathrm{I}$-albumin (9). However, the basis of fragment D-induced endothelial injury is not known. In recent years, studies have demonstrated that plasminogen activators (PAs), plasminogen activator inhibitors (PAIs), and plasmin systems play a critical role in remodeling of the extracellular matrix and regulating cell-cell and cell-substratum adhesion (10-13). Endothelial cells can synthesize and secrete tissuetype plasminogen activator ( tPA) and urokinase-type plasminogen activator (UPA) (14-16). uPA is associated with cellsubstratum contact points $(13,16)$ and may be important in mediating cell detachment. Because FDPs are known to interact with PAs $(17,18)$ and fragment D causes endothelial cytoskeletal F-actin reorientation (9) and cell detachment (8), we hypothesized that fragment D-induced release of PAs by endothelial cells may be a critical event in mediating proteolysis of subendothelial proteins and thus may result in endothelial cell detachment. In the present study, we examined the effects of FDP fragment D on endothelial-derived PAs and their potential role in injuring the endothelial cell barrier.

\section{Methods}

\section{Reagents}

Plasmin inhibitor Val-Phe-Lys-chloromethylketone, urokinase inhibitor dansyl-Glu-Gly-Arg chloromethyl ketone (dansyl-GGACK), and thiobenzyl benzyloxycarbonyl-L-lysinate (Cbz-Lys-S-Bzl) were purchased from Calbiochem Corp. (La Jolla, CA). Chromogenic substrate for plasmin Val-Leu-Lys-pNA (S-2251) was purchased from Kabivitrum, Inc. (Stockholm, Sweden). Aprotinin was purchased from Mobay Chemical Corp. (New York, NY). Human urokinase and goat anti-porcine heart tPA polyclonal antibodies (Abs) were purchased from American Diagnostica Inc. (Hartford, CT). A rabbit anti-bovine uPA polyclonal Ab was a generous gift from Dr. D. Rifkin, New York University, New York. A goat anti-human urokinase polyclonal $\mathrm{Ab}$ was provided by Dr. N. Gilboa, Pittsburgh Children's Hospital, Pittsburgh, PA. The cross-reactivity of anti-porcine tPA and anti-human uPA Abs with bovine pulmonary artery endothelial cell (BPAEC) plasminogen activators was tested by ELISA and immunoblot analysis using a microfiltration apparatus (Bio-Dot; Bio-Rad Laboratories, Rich- 
mond, CA). Rabbit anti-human fragment D polyclonal Abs 5/59B and 1747 were generously supplied by Dr. B. Kudryk, New York Blood Center, New York. Goat anti-human fragment $D$ and fragment E polyclonal Abs were purchased from ICN ImmunoBiologicals, ICN Biomedicals, Inc. (Lisle, IL). Purified human fibronectin was provided by Dr. F. Blumenstock, The Albany Medical College, Albany, NY.

\section{Fibrinogen purification}

Human fibrinogen was purified from fresh plasma (obtained from $\mathrm{Al}-$ bany Red Cross, Albany, NY) by a modified glycine precipitation procedure (19). Residual plasminogen and fibronectin were removed by lysine-Sepharose and gelatin-Sepharose affinity columns (Pharmacia Inc., Piscataway, NJ), respectively. Purified fibrinogen was $>96 \%$ clottable and showed intact $\alpha(65 \mathrm{kD}), \beta(50 \mathrm{kD})$, and $\gamma(45 \mathrm{kD})$ chains when analyzed on SDS-PAGE. Overloading of fibrinogen on reduced SDS-PAGE did not reveal any detectable bands of 220 and $90 \mathrm{kD}$ corresponding to fibronectin and Glu-plasminogen, respectively.

\section{Preparation of fragment $D$ and $E$}

Purified fibrinogen was digested with human plasmin (fibrinogen/ plasmin $=300: 1$ molar ratio) with $5 \mathrm{mM} \mathrm{Ca}^{2+}$ or $5 \mathrm{mM} \mathrm{EGTA} \mathrm{for} 5 \mathrm{~h}$ at $37^{\circ} \mathrm{C}$. The time course of plasmin digestion was monitored by SDSPAGE analysis. Plasmin digestion was terminated by adding excess Val-Phe-Lys-chloromethylketone.

Fragment $\mathrm{D}$ was isolated by QAE-Sephadex anion-exchange chromatography with modifications (20). The plasmin digest of fibrinogen was applied to a $2.5 \times 23 \mathrm{~cm}$ QAE-Sephadex column (Pharmacia Inc.) equilibrated in $0.1 \mathrm{M}$ ethylene diamine acetate (EDA) buffer, $\mathrm{pH} 8.0$. Fragment $\mathrm{D}$ was eluted from the column in two peaks. One portion of the fragment $D$ (peak 1) was eluted with the equilibration buffer and the remainder (peak 2 ) was eluted by EDA buffer, $\mathrm{pH}$ 6.5. Fragment $\mathrm{E}$ (peak 3 ) was eluted with $0.2 \mathrm{M}$ sodium acetate buffer, $\mathrm{pH}$ 4.4. The $\mathrm{pH}$ of each pool was adjusted to 7.4 and dialyzed against $10 \mathrm{mM}$ Tris, 0.15 $\mathrm{M} \mathrm{NaCl}, \mathrm{pH}$ 7.4. Fragments $\mathrm{D}$ and $\mathrm{E}$ were further purified by gel filtration on Sephadex G-200 and Sephacryl S-200 columns (Pharmacia Inc.), respectively. The purity of various preparations was determined by SDS-PAGE and scanning densitometry. Protein concentration of fragments $D$ and $E$ were measured by absorbance at $280 \mathrm{~nm}$ in $0.1 \mathrm{~N} \mathrm{NaOH}$ using extinction coefficients of $\mathrm{E}_{1 \mathrm{~cm}}^{1 \%}=20.8$ and 10.1, respectively (21). After extensive dialysis against PBS (pH 7.4), the purified fragments were passed through a $0.22-\mu \mathrm{m}$ hydrophilic nylon sterile filter (Lida Manufacturing Corp., Kenosha, WI) and a Detoxigel affinity Pak (Pierce Chemical Co., Rockford, IL) to remove possible endotoxin contamination. Preparations were stored at $-70^{\circ} \mathrm{C}$ until the experiments.

Fragment D prepared with either $5 \mathrm{mM} \mathrm{Ca}^{2+}$ or $5 \mathrm{mM}$ EGTA showed single bands on SDS-PAGE with relative molecular masses $\left(M_{r}\right)$ of $94\left(D_{94}\right)$ and $80 \mathrm{kD}\left(D_{80}\right)$, respectively. Fragment E migrated as a single band with a relative molecular mass of $50 \mathrm{kD}$. Both purified fragments $D$ and $E$ were further characterized by Western blotting and immunodiffusion assays. The purified fragments $D$ and $E$ reacted only with their corresponding Abs without detectable cross-contamination. Both preparations were free of contamination from plasminogen, plasmin, or PAs using assay of PA activity, plasmin activity, and ${ }^{125}$ I-fibrinogen degradation.

\section{Plasminogen and plasmin preparations}

Human native Glu-plasminogen and Lys-plasminogen were isolated from plasma and Cohn fraction III pastes (gift from Dr. H. S. Kingdon, Highland Laboratories, Glendale, CA) by lysine-Sepharose affinity chromatography as described (22). Plasmin was prepared by activation of Lys-plasminogen with urokinase and characterized by $p$-nitrophenyl- $p^{\prime}$-guanidinobenzoate titration and SDS-PAGE analysis as reported (22).

\section{Vitronectin purification}

Human vitronectin was purified from fresh plasma by heparin-Sepharose 4B affinity chromatography in the presence of urea as described by
Yatohgo et al. (23). SDS-PAGE analysis of the purified vitronectin revealed two bands with the molecular masses of 75 and $65 \mathrm{kD}$ as reported (19).

\section{IgG purification}

IgGs were purified from antisera (anti-bovine uPA, anti-fragment D, and anti-fragment $\mathrm{E}$ ) or nonimmune rabbit serum using protein $\mathrm{A}-\mathrm{Se}$ pharose affinity chromatography according to the manufacturer's instruction (Pharmacia Inc.). Purified IgGs were dialyzed against PBS, passed through a $0.22-\mu \mathrm{m}$ sterile filter, and stored at $4^{\circ} \mathrm{C}$.

\section{Endothelial cell culture}

BPAEC (CCL-209) was obtained from the American Type Culture Collection (Rockville, MD) at 16th passage. BPAEC were grown in Dulbecco's Modified Essential Medium (DMEM) (Gibco Laboratories, Grand Island, NY) with the supplement of $20 \%$ FCS (Gibco Laboratories), $50 \mu \mathrm{g} / \mathrm{ml}$ of gentamycin, and $0.1 \mu \mathrm{M}$ of Modified Eagle NonEssential Amino Acids (Gibco Laboratories). This endothelial cell line was characterized by uptake of acetylated LDL and presence of angiotensin-converting enzyme and von Willebrand factor.

BPAEC were seeded onto 12-well culture dishes and grown to confluency in DMEM ( 3-4 d postseeding). The cells were washed $2 \times$ with HBSS and incubated with fragment D or fragment $E$ in DMEM (final volume $400 \mu \mathrm{l}$ ) containing $20 \mathrm{mM}$ Hepes (Sigma Chemical Co., St Louis, MO) and 0.5\% BSA (Sigma Chemical Co.), pH 7.4, without phenol red. Previous studies showed that these cells remained a confluent monolayer after $72 \mathrm{~h}$ in serum-free culture medium. Conditioned medium was collected at different time points after the interventions. The cells were washed $(2 \times)$ with HBSS and lysed in $400 \mu \mathrm{l}$ of $0.5 \%$ Triton X-100 for assaying PAs and plasmin or trypsinized for cell counts. The Triton-insoluble extracellular matrix was washed $(2 \times)$ with HBSS for plasmin assay or scraped into SDS sample buffer for gel analysis.

\section{Assay of endothelial cell detachment}

Endothelial cells were challenged with fragment D, fragment E, or control DMEM for different periods. Cell morphology was examined by phase contrast microscopy. The detached cells were removed at different time points by washing $(3 \times)$ with HBSS. The remaining attached cells were detached from the underlying substratum by brief trypsin exposure and were counted using a hemocytometer. The viability of both attached and detached endothelial cells was determined by trypan blue dye exclusion. For analysis, the percent of detached cells was calculated from remaining attached cells by number of control cells number of treated cells/number of control cells $\times 100$.

\section{Measurement of PAs}

Measurement of antigens. A modified sandwich ELISA (24) was used to measure uPA in conditioned media and cell lysates. Wells of 96-well microtiter plates were coated with a rabbit anti-bovine uPA polyclonal antibody as the capturing antibody. A goat anti-human uPA polyclonal antibody (which cross-reacted with bovine uPA) was used as the primary antibody. When compared with human urokinase standard, uPA concentrations of the assayed samples were in the range of 10 to $200 \mathrm{ng} / \mathrm{ml}$. The absorbance values at $410 \mathrm{~nm}\left(\mathrm{~A}_{410}\right)$ of control and fragment D-treated groups were compared to reflect uPA antigen levels. tPA antigen in the conditioned media was measured by ELISA using goat anti-porcine heart tPA polyclonal antibody, which crossreacted with bovine tPA.

Chromogenic analysis of total $P A$ activity. Total PA activity (which comprised both uPA and TPA) was measured using the plasminogen activation assay of Coleman and Green (25). Briefly, $10 \mu \mathrm{l}$ of sample or uPA standard was incubated with $50 \mu \mathrm{l}$ of $0.12 \mathrm{mg} / \mathrm{ml}$ Lys-plasminogen in $0.12 \mathrm{M}$ glycine buffer containing $0.05 \% \mathrm{BSA}$ (Sigma Chemical Co.), $\mathrm{pH} 8.5$ at $37^{\circ} \mathrm{C}$ for $45 \mathrm{~min}$. The reaction mixture was then incubated with $1.74 \mathrm{mg} / \mathrm{ml}$ DTNB in PBS buffer containing $0.2 \mathrm{M} \mathrm{PO}_{4}$, $0.2 \mathrm{M} \mathrm{NaCl}$, and $0.01 \%$ Triton X-100, pH 7.5 (Ellman's reagent) and Cbz-Lys-S-Bzl in the PBS/Triton buffer at $37^{\circ} \mathrm{C}$ for $60 \mathrm{~min}$. The reac- 
tion was terminated by adding soybean trypsin inhibitor $(1 \mathrm{mg} / \mathrm{ml}$; $100 \mu \mathrm{l} /$ tube) and the absorbance of the samples at $412 \mathrm{~nm}$ was read against blank $\mathrm{H}_{2} \mathrm{O}$ and corrected by plasminogen blank. The average of the duplicated absorbance values was used to calculate equivalent CTA Committee for Thrombolytic Activity (CTA) units/ml $(\mathrm{U} / \mathrm{ml})$ against a regression line of human uPA standards. For assaying fragment D-containing conditioned media, the calibration curve of the standard was made using same concentrations of fragment $D$ in the assay mixture.

Zymographic analysis of $P A$ activity. The PAs in conditioned media and cell lysates were analyzed by casein/plasminogen SDS-PAGE zymography with modifications $(26,27)$. The assay was performed on a mini-dual slab gel apparatus (Bio-Rad Laboratories). Lys-plasminogen (final concentration of $0.03 \mathrm{mg} / \mathrm{ml}$ ) and casein (final concentration of $1 \mathrm{mg} / \mathrm{ml}$ ) were copolymerized in a gradient SDS polyacrylamide gel. Samples of conditioned media and cell lysate were unboiled and nonreduced. After electrophoresis at $200 \mathrm{~V}$ for 45 to $60 \mathrm{~min}$ at $4^{\circ} \mathrm{C}$, the gels were soaked in $2.5 \%$ Triton X-100 in $\mathrm{H}_{2} \mathrm{O}$ at room temperature for $60 \mathrm{~min}$ and incubated with $0.1 \mathrm{M}$ glycine buffer $(\mathrm{pH} 8.3)$ at $37^{\circ} \mathrm{C}$ for 3 to $5 \mathrm{~h}$ (longer incubation time was used for detecting tPA). The gels were stained with Coomassie blue followed by destaining. Plasminogen-independent caseinolytic activity was determined by analyzing the same samples on gels containing casein but without plasminogen. The uPA or IPA activities were characterized by their respective molecular weights and using plasminogen/casein gels copolymerized with antibodies against tPA or UPA $(27,28)$.

\section{Measurement of plasmin activity}

Conditioned media and Triton-cell lysates were incubated with plasmin substrate Val-Leu-Lys-pNA (S-2251, final concentration of 0.35 $\mathrm{mM}$ ) in a 96-well microtiter plate ( final volume of $200 \mu \mathrm{l} /$ well) for 60 min at room temperature. The Triton X-100-insoluble matrix was incubated with S-2251 for $60 \mathrm{~min}$ and the reaction mixture was transferred into a 96-well plate for reading absorbance. Plasmin activity was measured by reading the absorbance at $410 \mathrm{~nm}$ and was calculated against a plasmin standard regression line.

Subendothelial ${ }^{125}$ I-fibrinogen and -vitronectin degradation Fibrinogen was iodinated using a modified chloramine-T method (29) and vitronectin was iodinated using an iodogen reaction kit according to manufacturer's instruction (Pierce Chemical Co.). Free ${ }^{125}$ I was removed by gel filtration on a Sephadex G-25 column (Pharmacia Inc.) and dialysis. The ${ }^{125} \mathrm{I}$-fibrinogen-or ${ }^{125} \mathrm{I}$-vitronectin-coated plates were prepared as described (30). The 24-well culture dishes were coated with $0.1 \mathrm{ml}$ of ${ }^{125} \mathrm{I}$-fibrinogen or ${ }^{125} \mathrm{I}$-vitronectin $(200,000 \mathrm{cpm} /$ well $)$ in the presence of $100 \mu \mathrm{g} / \mathrm{ml}$ corresponding unlabeled proteins. After drying at $40^{\circ} \mathrm{C}$ in an oven, the coated plates were blocked with $0.4 \mathrm{ml}$ of $1 \% \mathrm{BSA}$ in PBS at room temperature for $1 \mathrm{~h}$ followed by washing $(2 \times)$ with $1 \mathrm{ml}$ of PBS. The plates were then sterilized by ultraviolet light overnight, and cells were seeded with $2 \times$ density. The cells reached confluency within $48 \mathrm{~h}$ after seeding.

Confluent BPAEC monolayers grown on the ${ }^{125}$ I-fibrinogen- or ${ }^{125}$ I-vitronectin-coated surface were washed $3 \times$ with DMEM and challenged with control PBS or fragment D with or without the following agents: plasminogen, aprotinin, dansyl-GGACK, anti-uPA antibody, or nonimmune control IgG. Medium $(20 \mu \mathrm{l})$ from each well was counted at different times after fragment $D$ challenge. Radiolabeled protein-coated wells in the presence or absence of plasmin were used as negative and positive controls, respectively.

\section{Data analysis}

Data were presented as mean \pm SEM. Some values were normalized as percent of control. Values between two groups were compared using Student's $t$ test. Comparison of several experimental groups with one control group was made by Dunnett's multiple-range test. Scheffe's test was used to compare the differences among several groups. Data significantly different from the normal distribution were analyzed by nonparametric statistics (Statpac Program). Statistical significance was defined as $P<0.05$.

\section{Results}

\section{Fragment $D$-induced endothelial cell detachment}

BPAEC monolayers maintained the characteristic pattern of the intact confluent monolayer in serum-free DMEM for the study period of $48 \mathrm{~h}$ (Fig. $1 \mathrm{a}$ ). Treatment with fragment $\mathrm{D}(2$ $\mu \mathrm{M}$ ) for $8 \mathrm{~h}$ caused no significant morphological changes or cell detachment (Fig. $1 b$ ). Some cells were retracted at $12 \mathrm{~h}$ after fragment $\mathrm{D}$ challenge (Fig. $1 \mathrm{c}$ ). However, incubation with 2 $\mu \mathrm{M}$ fragment $\mathrm{D}$ for $24 \mathrm{~h}$ detached $50.8 \pm 4.0 \%(n=9)(P$ $<0.01$ ) of the cells from the substratum (Fig. $1 d$ and Table I). Lower concentrations of fragment $\mathrm{D}(0.5-1.0 \mu \mathrm{M})$ required longer incubation periods to produce the same effect. Fragment $\mathrm{D}$-induced cell detachment (i.e., $50.2 \pm 2.5 \%$ of cells were detached with exposure of $1 \mu \mathrm{M}$ for $36 \mathrm{~h}[n=6]$ ) was significantly reduced by coincubation with $0.8 \mathrm{mg} / \mathrm{ml}$ anti-fragment D antibody (IgG) 5/59B $(18.6 \pm 5.4 \% ;[n=3] P<0.01)$, whereas nonimmune control $\mathrm{IgG}$ had no significant effect $(45.1 \pm 2.8 \% ; P>0.05[n=3])$. To assess whether fragment D-induced endothelial cell detachment was reversible, BPAEC were incubated with $2 \mu \mathrm{M}$ fragment D for 2 to $4 \mathrm{~h}$ and the medium was removed by washing the cell layers $2 \times$ with fresh DMEM. There was no sign of cell detachment up to $72 \mathrm{~h}$, indicating that the effect of fragment $\mathrm{D}$ was reversible. BPAEC treated with $\leq 4 \mu \mathrm{M}$ of purified fibrinogen for $72 \mathrm{~h}$ did not show significant cell detachment (Fig. $1 e$ ). BPAEC treated with 4 $\mu \mathrm{M}$ of fragment $\mathrm{E}$ for $24 \mathrm{~h}$ caused less cell detachment compared with the fragment D-exposed cells (Fig. $1 f$ ).

Endothelial cell detachment produced by fragment $\mathrm{D}$ was independent of the $\mathrm{COOH}$-terminal sequence of the $\gamma$-chain on fragment $D$ because fragment $D_{80}$ (which lacks the $\gamma$-carboxyl sequence of fragment $D_{94}[31]$ ) produced a similar effect as fragment $\mathrm{D}_{94}$ (Table II).

The presence of $20 \%$ serum in the incubating medium potentiated cell detachment mediated by fragment $D$ (Table II). This effect was also seen with 10 or $5 \%$ of serum. Serum passed through a lysine-Sepharose column to remove plasminogen or heated at $56^{\circ} \mathrm{C}$ for $30 \mathrm{~min}$ to inactivate complement retained its potentiating activity.

\section{Effects of fragment $D$ on endothelial cell-derived $P A s$}

$P A$ Antigens. BPAEC incubated with $4 \mu \mathrm{M}$ fibrinogen showed no increase in uPA antigen concentration in the medium. In contrast, fragment $\mathrm{D}(2 \mu \mathrm{M})$ significantly increased uPA antigen concentration (Table III). Fragment $\mathrm{E}$ at $4 \mu \mathrm{M}$ induced a small (statistically insignificant) increase in uPA antigen in the medium, which was significantly less than with fragment $\mathrm{D}(P$ $<0.05$ ) (Table III).

Incubation of BPAEC with $2 \mu \mathrm{M}$ fragment D produced a time-dependent increase in UPA antigen in the conditioned medium; i.e., fragment $D$-treated endothelial cells increased the uPA antigen levels to $150.1 \pm 13.6(n=14)(P<0.01)$ and $148.1 \pm 11.4 \%(n=18)$ of the corresponding control values $(P$ $<0.01$ ) at 2 and $4 \mathrm{~h}$, respectively (Fig. 2). At 8 to $12 \mathrm{~h}$, the medium uPA antigen concentrations were similar to the control values $(P>0.05)$ (Fig. 2). Fragment $D$ did not cause significant changes in uPA antigen concentrations in the Triton X-100-soluble cell fraction.

Fragment D-challenged BPAEC monolayers also increased the tPA antigen concentration in the conditioned medium compared with controls (Fig. 3 ); i.e., challenge with $2 \mu \mathrm{M}$ fragment $\mathrm{D}$ for 2,4 , and $8 \mathrm{~h}$ increased tPA antigen to $182.2 \pm 18.0$ 

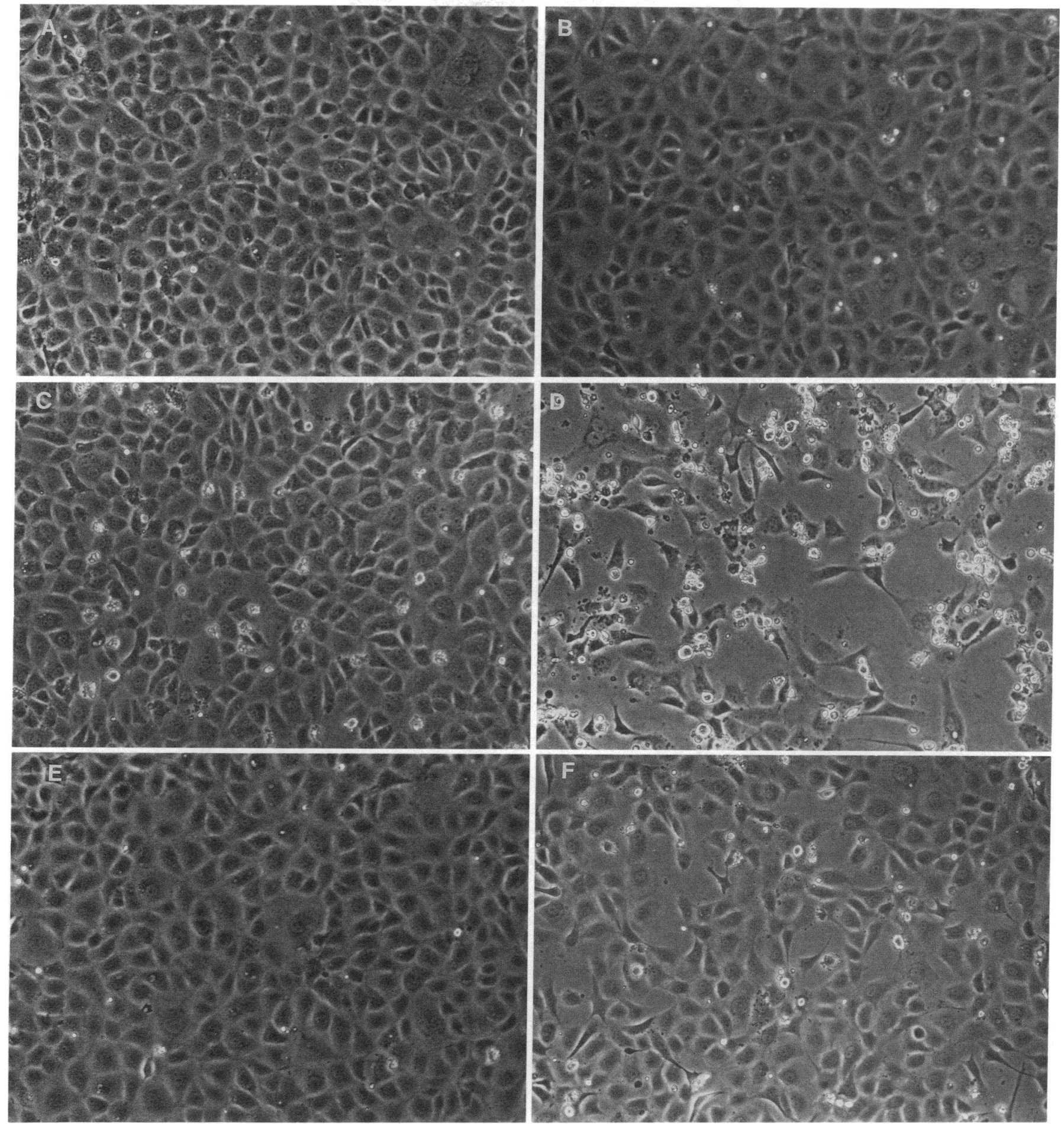

Figure 1. Time course of fragment D-induced BPAEC detachment. Endothelial cells were incubated with endothelial cells with fragment D, fibrinogen, fragment E, or control PBS in DMEM for various periods. The micrographs show BPAEC monolayers of $(a)$ control cells treated with PBS for $24 \mathrm{~h} ;(b)$ cells treated with $2 \mu \mathrm{M}$ of fragment D for $8 \mathrm{~h} ;(c)$ cells treated with $2 \mu \mathrm{M}$ of fragment D for $12 \mathrm{~h} ;(d)$ cells treated with 2 $\mu \mathrm{M}$ of fragment $\mathrm{D}$ for $24 \mathrm{~h} ;(e)$ cells treated with $4 \mu \mathrm{M}$ of fibrinogen for $24 \mathrm{~h}$; and $(f)$ cells treated with $4 \mu \mathrm{M}$ of fragment $\mathrm{E}$ for $24 \mathrm{~h}$.

$(n=20)(P<0.01), 164.2 \pm 9.1(n=26)(P<0.01)$, and $137.8 \pm 17.2 \%(n=16)(P<0.05)$ of the corresponding control values, respectively. At $12 \mathrm{~h}$, the tPA antigen levels were similar to the control value $(P>0.05)$ (Fig. 3$)$.

$P A$ activities. SDS-PAGE zymography indicated that untreated BPAEC monolayers constitutively released PAs into the incubating medium (Fig. $4 a$ ). More than $90 \%$ of the total PA activity in control BPAEC conditioned medium after $24 \mathrm{~h}$ incubation was inhibited by anti-bovine uPA IgG when analyzed by the chromagenic PA activity assay. Zymography analysis also indicated that most of the PA activity in control BPAEC conditioned medium was uPA $\left(M_{\mathrm{r}} \sim 48 \mathrm{kD}\right)$ (Fig. 4 
Table I. Effect of Fragment D on Bovine Pulmonary Artery endothelial Cell Detachment

\begin{tabular}{ccccc}
\hline & \multicolumn{4}{c}{ Attached cells* } \\
\cline { 2 - 5 } Time & Control & $n$ & Fragment D & $n$ \\
\hline$h$ & $\times 10^{5}$ cells per well & & $\times 10^{5}$ cells per well \\
4 & $5.94 \pm 0.16$ & 4 & $5.88 \pm 0.24$ & 4 \\
8 & 6.05 & 2 & 6.10 & 2 \\
12 & 5.67 & 2 & $5.70 \pm 0.44$ & 3 \\
16 & $5.70 \pm 0.28$ & 4 & $5.11 \pm 0.13$ & 4 \\
24 & $6.19 \pm 0.18$ & 8 & $3.04 \pm 0.25^{*}$ & 9 \\
\hline
\end{tabular}

Endothelial monolayers were challenged with $2 \mu \mathrm{M}$ fragment $\mathrm{D}$ for the indicated periods. Cells were washed and remaining attached cells were counted (see Methods for details). Values are expressed as mean \pm SEM.

* Different from time-matched control group $(P<0.01)$.

$a$ ), which was eliminated when anti-uPA Ab was copolymerized in the gel. Anti-uPA Ab also inhibited the caseinolytic activity of a 30-kD protein (Fig. $4 a$ ), which is a proteolytic product of uPA generated by plasmin cleavage $(10-12,14)$. Fragment $\mathrm{D}$ increased the $48-\mathrm{kD}$ uPA activity in the medium at $4 \mathrm{~h}$, whereas the uPA activities at 8 and $24 \mathrm{~h}$ were similar to or lower than the constitutive release from control cells (Fig. 4 $a$ ). The increase in uPA induced by fragment $\mathrm{E}$ at $4 \mathrm{~h}$ was less than that observed with fragment $D$.

Zymographic analysis indicated that fragment $D$ enhanced a band $\left(M_{r}=70,000\right)$ in the conditioned medium at $8 \mathrm{~h}$ (Fig. 4 a). The 70-kD protein was identified to be tPA because it was inhibited by copolymerizing with an anti-tPA antibody in casein-plasminogen gel. The increase in TPA activity induced by fragment $D$ was invariably less than the increase in uPA activity (Fig. $4 a$ ).

The fragment D-induced increase in PA activity assessed by the activity assay was evident after 30 min of incubation ( $n$ $=4)(P<0.05)$ (Fig. $4 b$ and Table IV). The response peaked within $2 \mathrm{~h}(201.6 \pm 14.9 \%)(n=18)(P<0.01)$ compared with

Table II. Effects of Different Preparations of Fragment D with or without Serum on Bovine Pulmonary Artery Endothelial Cell Detachment

\begin{tabular}{lcc}
\hline \multicolumn{1}{c}{ Group } & $n$ & Attached cells \\
\hline & & $\times 10^{5}$ cells per well \\
Control & 8 & $6.19 \pm 0.18$ \\
Fragment $D_{94}(2 \mu \mathrm{M})$ & 9 & $3.04 \pm 0.25^{*}$ \\
Fragment $D_{80}(2 \mu \mathrm{M})$ & 5 & $3.35 \pm 0.19^{*}$ \\
Fragment $D_{94}(2 \mu \mathrm{M})$ & & \\
$\quad$ w/20\% serum & 5 & $1.87 \pm 0.25^{\ddagger *}$ \\
\hline
\end{tabular}

Endothelial monolayers were challenged with $2 \mu \mathrm{M}$ fragment $\mathrm{D}$ with or without $20 \%$ serum (in DMEM) or $2 \mu \mathrm{M}$ fragment $\mathrm{D}_{80}$ for $24 \mathrm{~h}$. Cell layers were washed and remaining attached cells were counted (see Methods for details). Values are shown as mean \pm SEM.

* Different from control $(P<0.01)$.

₹ Different from other fragment $\mathrm{D}$-treated groups $(P<0.05)$.
Table III. Effect of Fibrinogen and Its Derivatives on uPA Antigen in the Conditioned Media of Bovine Pulmonary Artery Endothelial Cells

\begin{tabular}{lll}
\hline \multicolumn{1}{c}{ Group } & $n$ & Absorbance at $410 \mathrm{~nm}$ \\
\hline Control & 4 & $0.500 \pm 0.054$ \\
Fibrinogen $(4 \mu \mathrm{M})$ & 4 & $0.526 \pm 0.051$ \\
Fragment $\mathrm{D}(2 \mu \mathrm{M})$ & 4 & $0.959 \pm 0.019^{* \ddagger}$ \\
Fragment $\mathrm{E}(4 \mu \mathrm{M})$ & 4 & $0.602 \pm 0.043$ \\
\hline
\end{tabular}

Endothelial monolayers were challenged by fibrinogen $(4 \mu \mathrm{M})$, fragment $\mathrm{D}(2 \mu \mathrm{M})$, or fragment $\mathrm{E}(4 \mu \mathrm{M})$ for $2 \mathrm{~h}$. The uPA antigen levels were measured by ELISA (see Methods for details). The values are expressed as mean \pm SEM.

* Different from control $(P<0.05)$.

${ }^{\ddagger}$ Different from fibrinogen and fragment $\mathrm{E}$ groups $(P<0.05)$.

the control value (Fig. $4 b$ ). The PA activity in the conditioned medium of fragment D-treated BPAEC gradually returned to the time-matched control levels after $6 \mathrm{~h}$ (Fig. $4 a$ and Table IV). After $12 \mathrm{~h}$, the PA activity in the media was less than the control value. The results of the PA activity assay were consistent with that of zymographic analysis (Fig. $4 a$ vs. b). The effect of fragment $D$ in increasing PA activity in the medium was also concentration dependent (Fig. 5, $a$ and $b$ ).

Effect of fragment $D$ on endothelial cell-associated plasmin activity

Incubation of endothelial monolayers with $2 \mu \mathrm{M}$ of fragment $\mathrm{D}$ increased the cell-associated plasmin activity at $2 \mathrm{~h}$ (Fig. 6).

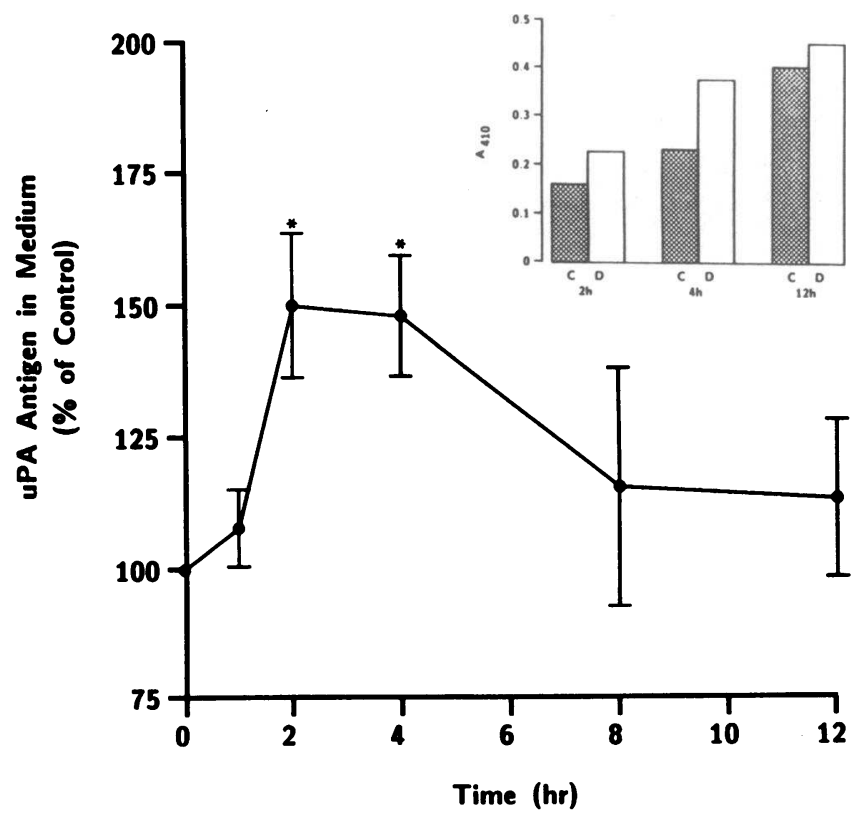

Figure 2. Effect of fragment D on uPA antigen concentration in the BPAEC-conditioned medium. Endothelial monolayers were incubated with $2 \mu \mathrm{M}$ fragment D or control PBS in DMEM for the indicated periods. The percent of control values at each time point was calculated (experimental/control $\times 100$ ). Data are shown as mean \pm SEM. *Comparison with control $(P<0.01)$. Insert shows representative experiments, shaded bar $(C)$, control; open bar $(D)$, fragment $D$ treatment. 


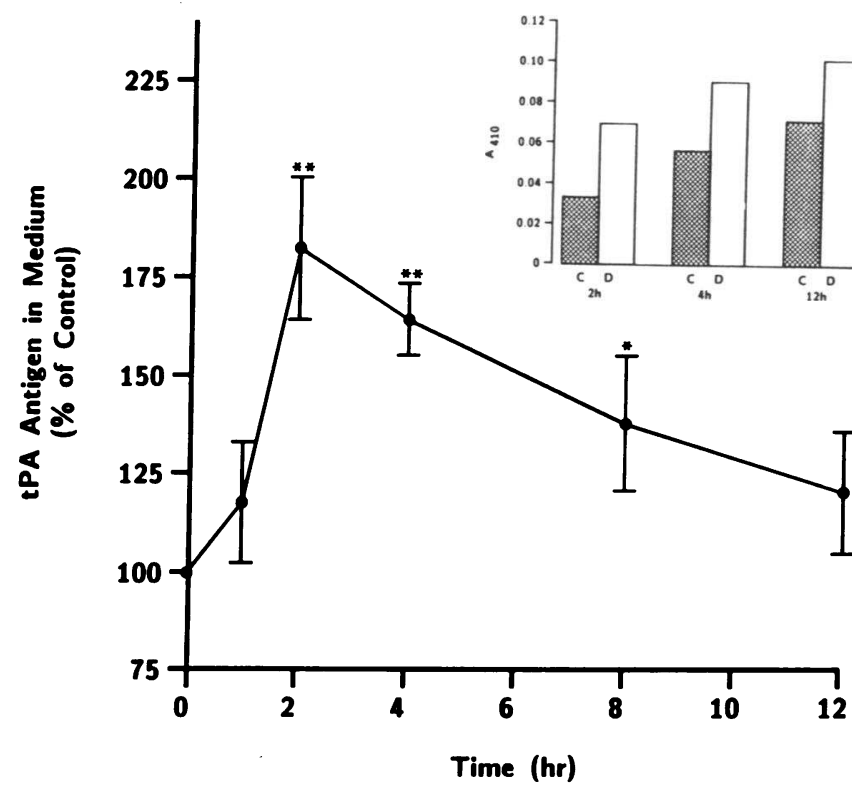

Figure 3. Effect of fragment D on TPA antigen concentration in BPAEC-conditioned medium. Endothelial monolayers were incubated with $2 \mu \mathrm{M}$ fragment D or control PBS in DMEM for the indicated periods. The percent of control values at each time point was calculated (experimental/control $\times 100)$. Data are shown as mean \pm SEM. Comparison with control $\left({ }^{* *} P<0.01 ;{ }^{*} P<0.05\right)$. Insert shows representative experiments, shaded bar $(C)$, control; open bar $(D)$, fragment $\mathrm{D}$ treatment.
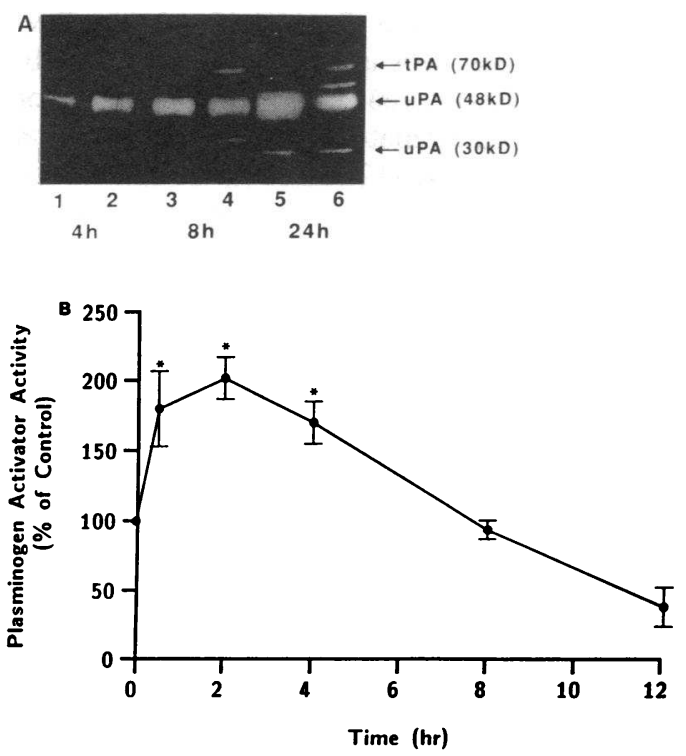

Figure 4. (a) Effect of fragment D on PA activity in BPAEC-conditioned medium (zymographic analysis). Endothelial cells were incubated with fragment D $(2 \mu \mathrm{M})$ or control PBS in DMEM for the indicated periods. PA activities were analyzed on a 5-20\% gradient SDS acrylamide-casein/plasminogen mini-slab gel. Unboiled samples $(10 \mu \mathrm{l})$ were applied to each lane. From left to right the paired lanes ( 1 and 2,3 and 4,5 and 6) represent the samples obtained at 4, 8 , and $24 \mathrm{~h}$, respectively. Samples in lanes 1,3 , and 5 were from control cells, and examples in lanes 2,4 , and 6 were from fragment D-treated cells. Arrows indicate the PAs with relative molecular mass values. $(b)$ Endothelial cells were incubated with fragment $D(2 \mu \mathrm{M})$ or control PBS in DMEM for the indicated periods. Data are shown as mean \pm SEM. ${ }^{*}$ Comparison with control $(P<0.05)$.
Table IV. Effect of Fragment D on Plasminogen Activator Activity in Bovine Pulmonary Artery Endothelial Cell-Conditioned Medium

\begin{tabular}{lcrcr}
\hline & \multicolumn{4}{c}{ PA activity } \\
\cline { 2 - 5 } Time & Control & \multicolumn{1}{c}{$n$} & Fragment D & $n$ \\
\hline$h$ & $U / m l$ & & $U / m l$ & \\
& & & $0.302 \pm 0.023^{*}$ & 4 \\
1 & $0.175 \pm 0.017$ & 4 & $0.420 \pm 0.117^{*}$ & 6 \\
2 & $0.250 \pm 0.048$ & 6 & $0.749 \pm 0.168^{*}$ & 18 \\
4 & $0.388 \pm 0.066$ & 17 & $0.770 \pm 0.071^{*}$ & 14 \\
6 & $0.452 \pm 0.055$ & 14 & $1.292 \pm 0.077^{*}$ & 6 \\
8 & $0.963 \pm 0.102$ & 6 & $1.377 \pm 0.184$ & 6 \\
12 & $1.522 \pm 0.142$ & 6 & $0.704 \pm 0.327$ & 4
\end{tabular}

Endothelial cells were incubated with $2 \mu \mathrm{M}$ of fragment D or control PBS in DMEM for the indicated periods. PA activity is determined by the activity assay (see Methods for details). The values are shown as mean \pm SEM.

${ }^{*}$ Different from control $(P<0.05)$.

The plasmin activity remained elevated at $12 \mathrm{~h}(n=4 ; P$ $<0.01$; Fig. 6). The plasmin activity was not detectable in the conditioned medium or Triton-insoluble matrix fractions. Fragment $\mathrm{E}(4 \mu \mathrm{M})$ also increased the cell-associated plasmin activity from the control value of $0.295 \pm 0.014$ to $0.363 \pm 0.018$ $\mathrm{nM} /$ liter $(P<0.05)$ after $12 \mathrm{~h}$ of incubation; however, this effect was less than that caused by $2 \mu \mathrm{M}$ of fragment $\mathrm{D}(P$ $<0.05$ ).

\section{Effects of fragment $D$ on degradation of subendothelial proteins}

BPAEC grown on ${ }^{125}$ I-fibrinogen- or ${ }^{125}$ I-vitronectin-coated surfaces formed characteristic confluent monolayers. Fragment D challenge ( $1 \mu \mathrm{M})$ for 2,4 , and $8 \mathrm{~h}$ increased the release of subendothelial ${ }^{125} \mathrm{I}$-fibrinogen fragments into the medium (Table V). At 2, 4, and $8 \mathrm{~h}$, the fragment $\mathrm{D}$-induced release of ${ }^{125}$ I-fibrinogen fragments increased from control values of $550 \pm 85,888 \pm 89$, and $1154 \pm 77$ to $760 \pm 87(P<0.05)$, $1094 \pm 80(P<0.05)$, and $1482 \pm 49 \mathrm{cpm} /$ well $(P<0.05)$, respectively. Fragment $D$ challenge also increased the release in ${ }^{125}$ I-vitronectin fragments into the medium, which peaked at 4 $\mathrm{h}$ of fragment $\mathrm{D}$ challenge $(P<0.05$; Table $\mathrm{V})$. These results indicate that fragment $\mathrm{D}$-induced plasmin generation was capable of degrading subendothelial proteins.

Addition of Glu-plasminogen $(0.1 \mu \mathrm{M})$ augmented the release of ${ }^{125}$ I-fibrinogen fragments into the medium by 10 -fold. This response was inhibited by pretreatment of BPAEC with anti-bovine uPA antibody $(0.7 \mathrm{mg} / \mathrm{ml})$, uPA inhibitor (dansyl-GGACK) $\left(10^{-7} \mathrm{M}\right)$, or the plasmin inhibitor (aprotinin) $(200 \mathrm{U} / \mathrm{ml})$ (Fig. 7). Pretreatment of nonimmune rabbit IgG $(0.7 \mathrm{mg} / \mathrm{ml})$ showed no effect (Fig. 7). Similar results were obtained using BPAEC seeded on ${ }^{125}$ I-vitronectin-coated surfaces (data not shown).

\section{Effects of UPA and plasmin inhibitors on endothelial cell detachment}

Fragment D-induced endothelial cell detachment was decreased by $60 \%$ after pretreatment of BPAEC monolayers with $10^{-7} \mathrm{M}$ dansyl-GGACK $(n=4)(P<0.01), 200 \mathrm{U} / \mathrm{ml}$ of 

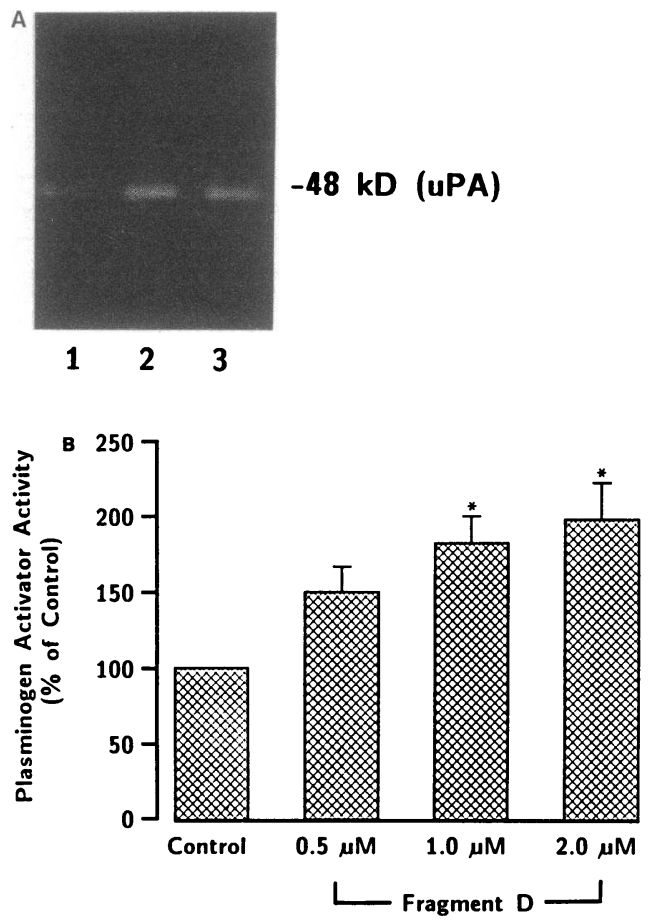

Figure 5. (a) Effects of different concentrations of fragment D on PA activity in BPAEC-conditioned medium (zymographic analysis). Endothelial cells were incubated with fragment $D$ or control PBS in DMEM for $2 \mathrm{~h}$. PA activities were analyzed on a 5-20\% gradient SDS acrylamide-casein/plasminogen mini-slab gel. Unboiled samples ( 5 $\mu \mathrm{l})$ were applied to each lane. Samples in the lanes are (1) control, (2) $1 \mu \mathrm{M}$ fragment $\mathrm{D}$, and (3) $2 \mu \mathrm{M}$ fragment $\mathrm{D}$. Bar, uPA relative molecular mass. $(b)$ Effect of different concentrations of fragment $\mathrm{D}$ on PA activity in the conditioned medium as determined by the activity assay. Endothelial cells were incubated with the indicated concentrations of fragment D or control PBS in DMEM for $2 \mathrm{~h}$. The percent of control values $=$ experimental $/$ control $\times 100$. Data are shown as mean \pm SEM. ${ }^{*}$ Comparison with control $(P<0.01)$.

aprotinin $(n=5)(P<0.01)$, or $0.7 \mathrm{mg} / \mathrm{ml}$ of anti-bovine uPA antibody $(n=3)(P<0.01)$ for $30 \mathrm{~min}$ before the fragment D challenge (Fig. 8). In contrast, the nonimmune IgG showed no protective effect (Fig. 8). These results indicate that

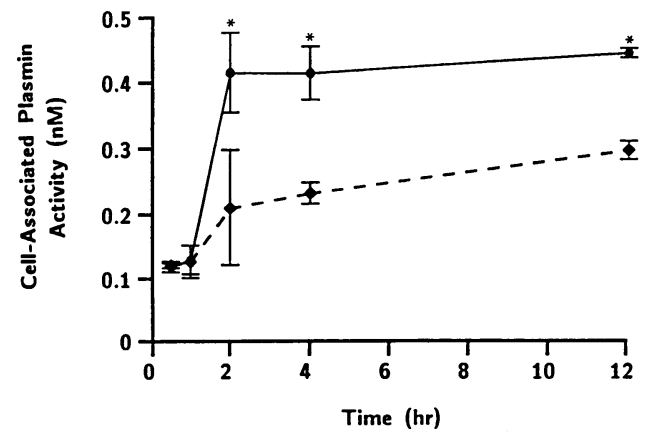

Figure 6. Effect of fragment D on BPAEC-associated plasmin activity. Endothelial cells were incubated with fragment $\mathrm{D}(2 \mu \mathrm{M})$ or control PBS in DMEM for the indicated periods. At the end of incubation, conditioned medium was removed and the cells were washed $2 \times$ with HBSS. The cells were then lysed in $0.5 \%$ Triton X-100 and plasmin activity was measured by the hydrolysis of S-2251 substrate in a 96well microtiter plate. Values are shown as mean \pm SEM. ${ }^{*}$ Comparison with control $(P<0.01) . \bullet-. \downarrow$, control; $\bullet-\bullet$, Fgt D.
Table V. Effect of Fragment D on Degradation of Radiolabeled Proteins Coating the Subendothelium

\begin{tabular}{|c|c|c|}
\hline \multirow[b]{2}{*}{ Time } & \multicolumn{2}{|c|}{ Medium radiolabeled fragments } \\
\hline & Fibrinogen & Vitronectin \\
\hline$h$ & \multicolumn{2}{|c|}{$\%$ of control } \\
\hline 2 & $125.7 \pm 9.8 \quad(9)^{\ddagger}$ & $117.8 \pm 17.6(6)$ \\
\hline 4 & $122.9 \pm 7.9 \quad(9)^{\ddagger}$ & $124.4 \pm 12.1(6)^{\ddagger}$ \\
\hline 8 & $128.4 \pm 4.2(5)^{\ddagger}$ & - \\
\hline 12 & $119.3 \pm 6.6(9)^{\ddagger}$ & $121.3 \pm 5.0$ \\
\hline 24 & $111.0 \pm 11.1(4)$ & $114.1 \pm 2.7$ \\
\hline
\end{tabular}

Confluent endothelial monolayers grown on plates coated with ${ }^{125} \mathrm{I}-$ fibrinogen, or ${ }^{125}$ I-vitronectin were washed $(3 \times)$ and then challenged with $1 \mu \mathrm{M}$ fragment D or control PBS in DMEM at time 0 . At various intervals, $20 \mu$ l of the conditioned media was sampled from each well and the radioactivity was counted.

* Percent $(\%)$ of control $=$ experimental/control $\times 100$. The numbers in parenthesis indicate the number of the samples.

Data are shown as mean \pm SEM.

${ }^{\ddagger}$ Different from time-matched control $(P<0.05)$.

fragment D-induced endothelial release of PAs and the subsequent generation of cell-associated plasmin are critical events in endothelial cell detachment.

\section{Discussion}

Endothelial cells produce UPA and tPA (10-12, 14-16). Several studies have shown that UPA is associated with cell-substratum adhesion sites $(10-12,16)$. During inflammation or upon the challenge with inflammatory mediators, endothelial cells express and secrete PAs (10-12, 24, 32), and hence these may contribute to endothelial injury. Secretion of PAs to the

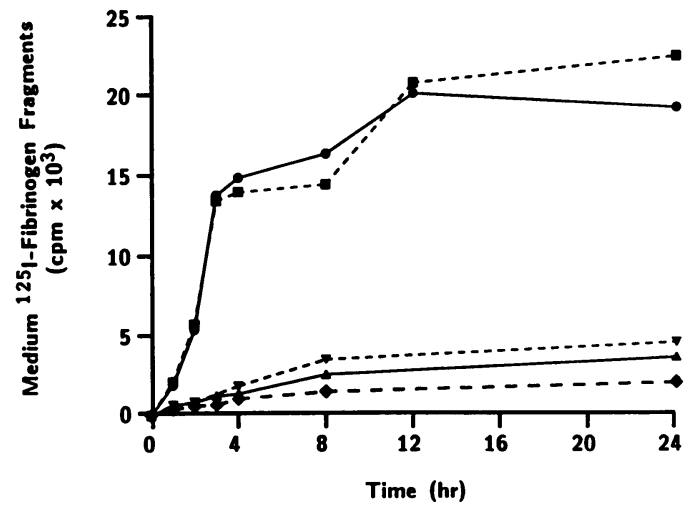

Figure 7. Effect of anti-uPA antibody and inhibitors on coated ${ }^{125}$ I-fibrinogen degradation in the presence of exogenous plasminogen. Confluent endothelial monolayer grown on ${ }^{125}$ I-fibrinogen-coated plates were pretreated with $0.7 \mathrm{mg} / \mathrm{ml}$ of anti-bovine $\mathrm{UPA}$ IgG $(a-$ $u P A I g G), 0.7 \mathrm{mg} / \mathrm{ml}$ nonimmune $\mathrm{IgG}(\operatorname{IgG}), 100 \mathrm{U} / \mathrm{ml}$ aprotinin, or $10^{-7} \mathrm{M}$ dansyl-GGACK $30 \mathrm{~min}$ before fragment $\mathrm{D}$ in the presence of $0.1 \mu \mathrm{M}$ Glu-plasminogen. At the indicated time points, $20 \mu \mathrm{l}$ of the conditioned media was sampled from each well and radioactivity was counted. Radioactivity values in the conditioned media are expressed as $\mathrm{cpm} \times 10^{3} /$ well. $\Delta-\Delta, \mathrm{Fgt}+\mathrm{a}-\mathrm{uPA}$ IgG; $\nabla-\ldots$, fat D + Aprotinin; - - - Fgt D + dansyl GGACK; - - - $\bullet$; Fgt D $+\mathrm{IgG} ; \bullet-\bullet$, Fgt D. 


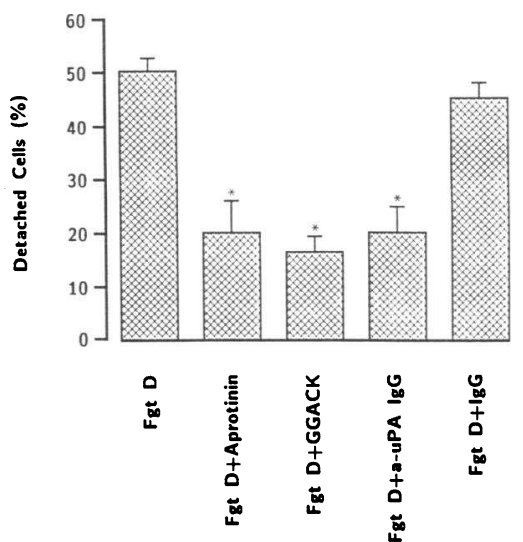

Figure 8. Effect of antiuPA antibody and inhibitors on fragment $D$ $(\mathrm{Fg}+\mathrm{D})$-induced BPAEC detachment. Endothelial cells were pretreated with $0.7 \mathrm{mg}$ / $\mathrm{ml}$ of anti-bovine uPA $\operatorname{IgG}(a-u P A \operatorname{IgG}), 0.7$ $\mathrm{mg} / \mathrm{ml}$ non-immune $\operatorname{IgG}(\operatorname{IgG}), 200 \mathrm{U} / \mathrm{ml}$ of aprotinin, or $10^{-7} \mathrm{M}$ dansyl-GGACK $(G G A C K)$ for $30 \mathrm{~min}$ before fragment $\mathrm{D}$ challenge. The cells were

incubated with $1 \mu \mathrm{M}$ fragment D or control PBS in DMEM for $36 \mathrm{~h}$. The detached cells were removed by washing $(3 \times)$ the cells with HBSS. The remainder of the attached cells was then detached by trypsinization and counted in a hemocytometer (as described in Methods). The percent of cells detached was calculated ([ number of control cells - number of treated remaining cells]/number of control cells $\times 100)$. Values are mean \pm SEM. ${ }^{*}$ Comparison with fragment D group $(P<0.01)$.

subendothelial sites may mediate the loss of endothelial barrier function subsequent to proteolysis of subendothelial proteins.

Previous studies have suggested a critical role for high molecular weight FDPs in the inflammatory response (1-3). One major high molecular weight FDP, fragment $\mathrm{D}$, is markedly elevated in the plasma of ARDS patients and has been linked to the development of lung vascular injury (4). Infusion of fragment $D$ in rabbits caused lung injury associated with increased lung vascular permeability $(6,7)$. In vitro studies indicate that fragment $D$ increases transendothelial macromolecular transport, alters cytoskeletal F-actin, and disrupts the endothelial cell monolayer $(8,9)$. In the present study, we observed that fragment D challenge for $24 \mathrm{~h}$ caused $\sim 50 \%$ detachment of BPAEC from the substratum, a process independent of the $\gamma$-carboxyl sequence of fragment D. The finding that $\gamma$-carboxyl peptide is not required for endothelial cell detachment is supported by previous studies $(8,9)$. Fragment $D$-induced endothelial cell detachment was reversible and was augmented by serum-containing medium. We speculate that serum contains factor(s) that interact with fragment $D$ and thus are capable of potentiating the effect of fragment $\mathrm{D}$. The nature of the serum cofactor(s) is not clear, but the present results ruled out plasminogen and complement constituents of serum.

Because fragment $\mathrm{D}$ is known to modulate PA-mediated plasminogen activation $(17,18,33)$, we examined the possibility that fragment D-induced endothelial cell detachment is mediated by release of endothelial-derived PAs and subsequent activation of cell-bound plasminogen. We tested the hypothesis that "upregulation" of endothelial cell-mediated fibrinolytic activity by fragment $D$ degrades the extracellular matrix and progressively detaches cells from the substratum.

The results indicated that purified fragment $D$ caused the release of UPA into the BPAEC-conditioned medium within 2 to $4 \mathrm{~h}$ of treatment, whereas fibrinogen showed no effect. Fragment D mainly increased 48-kD uPA and subsequently increased a $30-\mathrm{kD}$ uPA. The latter is a degradation product of the 48-kD uPA, generated by limited plasmin proteolysis of the $\mathrm{NH}_{2}$-terminal cell-binding domain of uPA (10-12). BPAEC produced relatively low levels of tPA after fragment $D$ challenge, which was also released into the medium in the similar time frame. The increase in PA activity was associated with elevated UPA and TPA antigen concentrations in the medium. In contrast to fragment $D, B P A E C$ challenged with fragment $E$ resulted in smaller increases in uPA antigen in the conditioned medium. The effects of fragment $E$ on endothelial release of uPA and plasmin generation were invariably less than those of fragment $D$, consistent with our previous observation that fragment $D$ was more potent in increasing endothelial permeability than fragment $\mathrm{E}(9)$.

Fragment $D$ increased the plasmin activity in BPAEC lysates, but not in the BPAEC-conditioned medium, suggesting that the generated plasmin remained cell bound. In contrast to the relatively transient increases in UPA and IPA activities, the increase in cell-associated plasmin activity was sustained for the duration of the study. This may be the result of absence of plasmin inhibitors in the serum-free medium or binding of plasmin to cell membrane may protect the plasmin from inactivation (34). We used the ${ }^{125}$ I-fibrinogen and ${ }^{125}$ I-vitronectin degradation assay (30) to determine whether the cell-bound plasmin altered the underlying extracellular matrix. Fragment $D$ challenge of BPAEC monolayers increased the release of ${ }^{125}$ I-fibrinogen and ${ }^{125}$ I-vitronectin fragments into the conditioned medium. The time course of degradation of the radiolabeled proteins paralleled the increase in the cell-associated plasmin activity. Because uPA secreted into the basolateral compartment of bovine endothelial cells is associated with focal contact points (16), the fragment D-induced increase in PA activity and the resultant increase in cell-associated plasmin may focally degrade underlying endothelial matrix and thus mediate the detachment of endothelial cells.

The role of plasmin generation by increased PA activity in mediating fragment D-induced endothelial cell detachment was examined using anti-uPA antibody, uPA inhibitor, or plasmin inhibitor. Pretreatment of endothelial cells with anti-uPA polyclonal antibody, uPA inhibitor (dansyl-GGACK), or plasmin inhibitor (aprotinin) prevented $\sim 60 \%$ of the fragment D-induced cell detachment, whereas nonimmune IgG (control antibody) showed no protection. These inhibitors were shown to prevent the proteolysis of the subendothelial-coated fibrinogen and vitronectin. These results support the hypothesis that endothelial cell detachment involves the release of PAs from BPAEC, generation of plasmin, and subsequent extracellular matrix proteolysis. This sequence linking upregulation of endothelial fibrinolytic activity to extracellular matrix degradation may mediate the observed fragment D-induced endothelial injury.

There was a significant delay in endothelial cell detachment in contrast to the relatively rapid increases in PA and plasmin activities. Although fragment $D$ significantly increased BPAEC-bound plasmin activity, the concentration of the generated plasmin was $\sim 0.5 \mathrm{nM} /$ liter. Therefore, at low concentrations of plasmin, there may be gradual and progressive disruption of cell-cell and cell-substratum adhesion sites, which may account for the delayed cell detachment. We cannot rule out the possibility that uPA/plasmin-independent mechanisms also contributed to fragment $\mathrm{D}$-induced endothelial cell detachment, particularly since the results indicated that the inhibitors and antibodies partially prevented endothelial cell detachment. We have observed that fragment $\mathrm{D}$ caused the release of two metalloproteinases $\left(M_{\mathrm{r}}=65\right.$ and $\left.95 \mathrm{kD}\right)$ into the 
endothelial-conditioned media in 12 to $24 \mathrm{~h}$, which were not inhibited by aprotinin and dansyl-GGACK (unpublished observation ). These enzymes may also contribute to the degradation of certain extracellular matrix proteins (e.g., collagen) and cell detachment.

We noted that there was a decline in PA activity after $8 \mathrm{~h}$ of fragment $D$ challenge whereas the antigen concentrations of both TPA and UPA did not decrease when compared with the time-matched controls. This suggests increased inactivation of PAs, which may be due to the endothelial secretion of PAIs $(10,11,12,16,24)$. Whether fragment $\mathrm{D}$ induces endothelial expression and secretion of PAIs and whether they modulate fragment D-induced endothelial cell detachment is unknown. However, fragment D-induced PA secretion caused the relatively rapid generation of plasmin, which was clearly the dominant factor responsible for degradation of extracellular matrix proteins and cell detachment as shown by the inhibitor studies.

In summary, we observed that purified fibrinogen fragment D increased the secretion of UPA and, to lesser extent, of tPA into the conditioned medium of BPAEC. Fragment D augmented the endothelial cell-associated plasmin activity and caused proteolysis of extracellular matrix proteins. Therefore, vascular endothelial injury after activation of fibrinolysis may be the result of fragment $\mathrm{D}$-induced release of endothelial-derived PAs, focal generation of plasmin, and resultant degradation of subendothelial matrix. This pro-inflammatory role of FDP fragment D may be important in the pathogenesis of tissue inflammation associated with activation of fibrinolysis.

\section{Acknowledgments}

We thank Ms. Lynn McCarthy for her secretarial assistance and Ms. Ginny Foster for her technical help.

Supported by National Institutes of Health grants HL-27016, HL45638, and HL-32418 and Grant-in-Aid from the American Heart Associate, New York State Affiliate.

\section{References}

1. Marder, V. J., S. D. Martin, C. W. Francis, and R. W. Colman. 1987. Consumptive thrombohemorrhagic disorders. In Hemostasis and Thrombosis. R. W. Colman, V. J. Marder, E. W. Salzman, and J. Hirsh, editors. J. B. Lippincott Company, Philadelphia. 975-1015.

2. Simon, R. H., and P. A. Ward. 1988. Adult respiratory distress syndrome. In Inflammation: Basic Principles and Clinical Correlates. J. I. Gallin, I. M. Goldstein, and R. Snyderman, editors. Raven Press, New York.

3. Malik, A. B. 1983. Pulmonary microembolism. Physiol. Rev. 63:11141207.

4. Haynes, J. B., T. M. Myers, T. M. Giclas, J. J. Franks, T. L. Petty. 1980. Elevated fibrin(ogen) degradation products in the adult respiratory distress syndrome. Am. Rev. Respir. Dis. 122:841-847.

5. Saldeen, T. 1983. Vasoactive peptides derived from degradation of fibrinogen and fibrin. In Molecular Biology of Fibrinogen and Fibrin. M. W. Mosesson, and R. F. Doolittle, editors. New York Academy of Sciences, New York. 424437.

6. Manwaring, D., D. Thorning, and P. W. Curreri. 1978. Mechanism of acute pulmonary dysfunction induced by fibrinogen degradation products. Surgery ( $S t$. Louis). 84:45-54.

7. Manwaring, D., and P. W. Curreri. 1980. The role of platelet aggregation and release in fragment D-induced pulmonary dysfunction. Ann. Surg. 192:103107.

8. Pang, C. V., W. R. Bell, D. Kaiser, and A. Wong. 1984. Disorganization of cultured vascular endothelial cell monolayers by fibrinogen fragment $\mathrm{D}$. Science (Wash. DC). 227:1487-1490.
9. Ge, M., T. J. Ryan, H. Lum, and A. B. Malik. 1991. Fibrinogen degradation product fragment $\mathrm{D}$ increases endothelial monolayer permeability. Am. J. Physiol. (Lung Cell. Mol. Biol.) 261:L283-L289.

10. Saksela, O., and D. B. Rifkin. 1988. Cell-associated plasminogen activation: regulation and physiological functions. Annu. Rev. Cell. Biol. 4:93-126.

11. Blasi, F., J. D. Vassalli, and K. Dano. 1987. Urokinase-type plasminogen activator. Proenzyme, receptor, and inhibitors. J. Cell Biol. 104:801-804.

12. Vassali, J. D., A. P. Sappino, and D. Belin. 1991. The plasminogen activator/plasmin system. J. Clin. Invest. 88:1067-1072.

13. Glass, W. F., R. A. Radnik, J. A. Garoni, and J. I. Kreisberg. 1988. Urokinase-dependent adhesion loss and shape change after cyclic adenosine monophosphate elevation in cultured rat mesangial cells. J. Clin. Invest. 82:1992-2000.

14. Levin, E. G., and D. J. Loskutoff. 1982. Cultured bovine endothelial cells produce both urokinase and tissue-type plasminogen activators. J. Cell Biol. 94:631-636.

15. Bykowska, K., E. G. Levin, D. C. Rijken, D. J. Loskutoff, and D. Collen. 1982. Characterization of a plasminogen activator secreted by cultured bovine aortic endothelial cells. Biochim. Biophys. Acta 703:113-115.

16. Murata, T., Y. Nakashima, C. Yasunaga, K. Maeda, and K. Sueishi. 1991. Extracellular and cell-associated localizations of plasminogen activators and plasminogen activator inhibitor-1 in cultured endothelium. Exp. Mol. Pathol. 55:105-118.

17. Stief, T. W., R. Marx, and N. Heimburger. 1989. Oxidized fibrin(ogen) derivatives enhance the activity of tissue type plasminogen activator. Thromb. Res. 56:221-228.

18. Lucas, M. A., D. L. Straight, L. J. Fretto, and P. A. McKee. 1983. The effects of fibrinogen and its cleavage products on the kinetics of plasminogen activation by urokinase and subsequent plasmin activity. J. Biol. Chem. 258:12171-12177.

19. Kazal, L. A., S. Amsel, O. P. Miller, and L. M. Tocantins. 1963. The preparation and some properties of fibrinogen precipitated from human plasma by glycine. Proc. Soc. Exp. Biol. Med. 113:989-994.

20. Chen, J. P., H. M. Shurley, and M. F. Vickroy. 1974. A facile separation of fragments $D$ and $E$ from the fibrinogen/fibrin degradation products of three mammalian species. Biochem. Biophys. Res. Commun. 61:66-71.

21. Marder, V. J., N. R. Schulman, and W. R. Carroll. 1969. High molecular weight derivatives of human fibrinogen produced by plasmin. I: Physicochemical and immunological characterization. J. Biol. Chem. 244:2111-2119.

22. Ryan, T. J., and M. C. Keegan. 1985. Photoaffinity labeling of functionally different lysine-binding sites in human plasminogen and plasmin. Biochim. Biophys. Acta. 830:187-194.

23. Yatohgo, T., M. Izumi, H. Kashiwagi, and M. Hayashi. 1988. Novel purification of vitronectin from human plasma by heparin affinity chromatography. Cell Struct. Funct. 13:281-292.

24. van Hinsbergh, V. W. M., E. A. vanden Berg, and G. Dooijewaard. 1990. Tumor necrosis factor induces the production of urokinase-type plasminogen activator by human endothelial cells. Blood. 75:1991-1998.

25. Coleman, P. J., and G. D. J. Green. 1981. A sensitive, coupled assay for plasminogen activator using a thiol ester substrate for plasmin. Ann. NY Acad. Sci. 370:617-626.

26. Huessen, C. H., and E. B. Dowdle. 1980. Electrophoretic analysis of plasminogen activators in polyacrylamide gels containing sodium dodecyl sulfate and copolymerized substrates. Anal. Biochem. 102:196-202.

27. Ryan, T. J., J. I. Seeger, S. A. Kumar, and H. W. Dickerman. 1984. Estradiol preferentially enhances extracellular tissue plasminogen activator of MCF-7 breast cancer cells. J. Biol. Chem. 259:14324-14327.

28. Caomiolo, S. M., G. Markus, L. S. Englander, M. R. Siota, G. H. Hobika, and S. Kohga. 1984. Plasminogen activator content and secretion in explants of neoplastic and benign human prostate tissues. Cancer Res. 44:311-318.

29. Miles, L. A., and E. F. Plow. 1985. Binding and activation of plasminogen on the platelet surface. J. Biol. Chem. 260:4303-4311.

30. Loskutoff, D. J., and T. Edgington. 1977. Synthesis of a fibrinolytic activator and inhibitor by endothelial cells. Proc. Natl. Acad. Sci. USA. 74:3903-3907.

31. Castellino, F. J. 1981. Recent advances in the chemistry of the fibrinolytic system. Chem. Rev. 81:431-446.

32. Grondahl, H. J., L. T. Kirkeby, E. Ralf kiaer, P. Kristensen, L. R. Lund, and K. Dano. 1989. Urokinase-type plasminogen activator in endothelial cells during acute inflammation of the appendix. Am. J. Pathol. 135:631-636.

33. Liu, J.-N. and V. Gurewich. 1991. A comparative study of the promotion of tissue plasminogen activator and pro-urokinase-induced plasminogen activation by fragments D and E-2 of fibrin. J. Clin. Invest. 88:2012-2017.

34. Bauer, P. I., R. Machovich, K. G. Buki, E. Csonka, S. A. Koch, and I. Horvath. 1984. Interaction of plasmin with endothelial cells. Biochem. J. 218:119-124. 